\title{
Crisis in Rhodesia
}

\author{
By C. A. R. Savory, MP
}

The author argues that Rhodesia's wildlife is in serious danger owing to poor or inadequate management in the national parks and reserves. He traces the stages leading up to the biological collapse of a habitat, which he says has already happened with the Tuli Circle National Land, and suggests that knowledge gained from game ranching and a new method of domestic stock management on privately owned lands has pointed the way for the future. Mr Savory is a consultant ecologist and his views are controversial, but the FPS believes that they merit serious consideration and should be heard.

$\mathbf{R}^{\mathrm{H}}$ HODESIA'S national lands are in a serious condition through lack of game and range management, apart from the artificial supply of water; and without population management this only aggravates the problems. Of the areas set aside to be preserved for the nation, the first to collapse biologically (Tuli Circle) has recently done so with what is probably irreparable destruction of the vegetation and the death of well over 30,000 head of game from starvation and other causes related to malnutrition. Parts of this 100,000 acre area are beyond reclamation, but it is hoped that its 'death' will not have been in vain and that the warning will serve to save other areas such as the Wankie National Park and the lower Zambesi Valley, both in danger of biological collapse. In all, six and a half million acres of national land in Rhodesia is deteriorating severely.

In one section of the Wankie National Park, surveyed by the writer with one of the park biologists in 1963, most species of ungulates had lost between 60 and 80 per cent of their calves of the year from malnutrition or associated causes. Wildebeest, the worst sufferers, had lost 80 per cent of the calves in their first six months. Reports from the Zambesi Valley areas in 1961 show that they are in an even worse state, and evidence in the Department of National Parks' 1967 annual report suggests that the deterioration continues despite the introduction of a controlled hunting scheme as a biopolitical substitute for management. A team of scientists visiting the area on behalf of the Ministry in 1962 had warned that the hunting scheme was inadequate and no substitute for management, but the report was ignored.

\section{Species Endangered}

Major species in danger of disappearing over much of Rhodesia through lack of management are black rhino, roan, tsessebe and giraffe. It may well be too late to save roan over much of their former Rhodesian range. Black rhino are in a serious position because, basically, they are limited to a last stronghold along the northern Zambesi region where their habitat is deteriorating through overpopulation, among other factors. The parts of their range where they are protected from hunting in an effort to save them, such as the Mana Pools game reserve and the Chewore wilderness area, are the places where ironically they are in gravest danger of killing themselves out and quite alarming numbers have been found dead over the last few years. 
As usual in such cases, creating an awareness of the situation has been the greatest problem; but it now seems that this is being achieved and it is hoped that action will follow, using the knowledge gained from the game management schemes that have been developed in Rhodesia in the last few years.

Scientific game management was started in 1960 on one private ranch, largely due to the work of Drs. R. F. Dasmann and A. S. Mossman; it has now spread to over 50 ranches which in 1964 produced in the region of 2,300,000 lb of venison. In 1963 the ranchers formed the Game Ranchers' Association to look after their interests which in 1965 affiliated to the Rhodesian National Farmers Union. This, it is hoped, will mean that game ranching will now be recognised and fully accepted for what it is - a new progressive form of agricultural land use for marginal lands with erratic rainfall.

The ranches are still in a very poor and worrying state, because, due to the fear of overcropping and the shortage of government personnel trained in game management, cropping has been at a level that merely slowed the deterioration; it has not improved the habitat sufficiently to safeguard the wildlife. The current position in Rhodesia is that, despite propaganda to the contrary, game ranching is failing in all of its aims. There is no scientific evidence that any game ranch in the country is ecologically sound, saving wildlife or halting the deterioration of land. There is at the same time no evidence to suggest game ranching itself is unsound - the failure is due to human administrative factors, to biopolitics. This lesson having been learned, it is hoped that the right action will now be taken. Gradually people are being brought to realise that under-cropping is one of the great dangers to wildlife in this country. By comparing the condition of these managed areas with the habitat deterioration on unmanaged game lands we have learned much about basic principles; if acted upon now, this knowledge could save both wildife and the habitat until such time as expensive and time-consuming detailed research shows the way to optimum management.

On the majority of privately owned ranches in Rhodesia the wildlife is in severe danger due to the gross habitat deterioration resulting from prolonged grazing by domestic stock. It has been found that as long as this persists wildlife management of larger species becomes almost meaningless in the long term. One is in effect merely buying time and preserving the populations for a little longer until the eventual desert is formed. In this connection, within the last two years a new method of handling domestic stock has been introduced in Rhodesia. This method of Short Duration Grazing (or Savory System) involves a quick rotation of stock which prevents overgrazing of any plant species and at the same time results in a rapid improvement of range and increased ability to carry both domestic stock and wildlife. A description of the method would be too lengthy for this paper, but at least one pilot ranch in a semi-arid region - which started in September 1966 with a very poor deteriorating range incapable, on conventional methods, of carrying 300 head of cattle and with impala and kudu populations showing high juvenile mortality - is now 


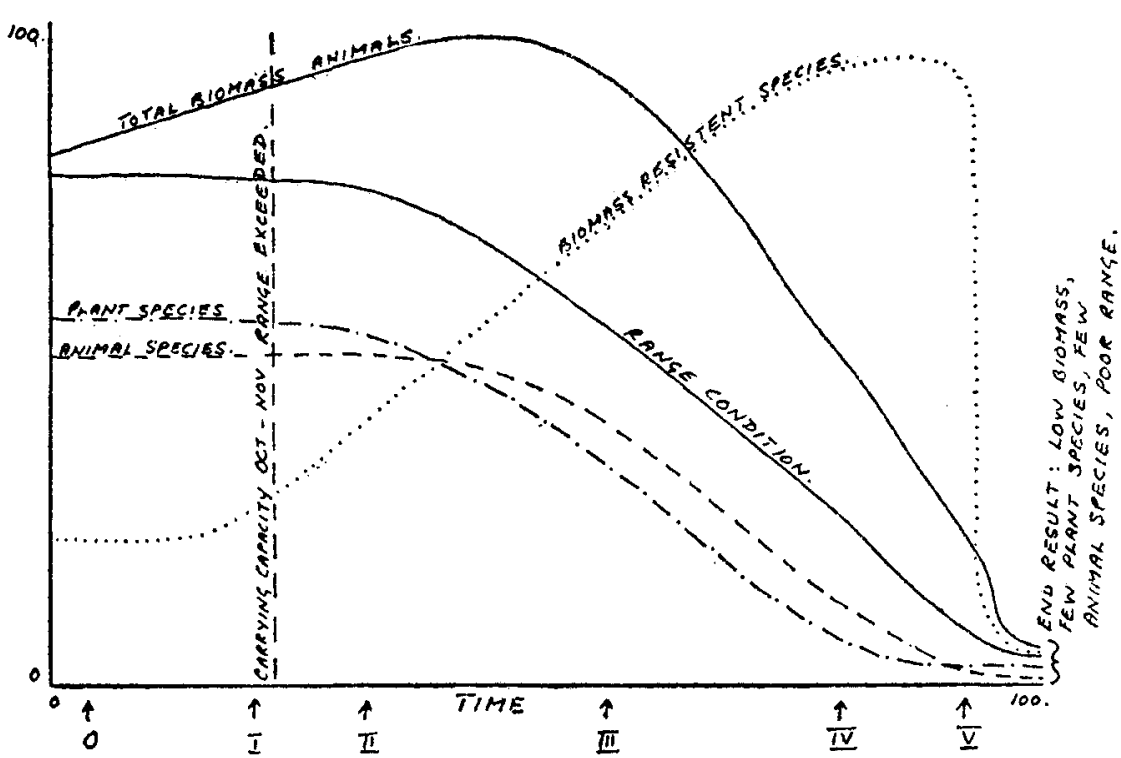

FIG. 1-Diagrammatic trend curves of biomass, number of animal species, number of plant species and range deterioration under unmanaged conditions.

carrying 1500 head of cattle with a still rapidly improving range and a wildlife population responding as expected. This method, already in practice on over 150 Rhodesian farms and ranches, is proving a long-sought means of range reclamation without destocking and offers hope for our major wildlife species on ranches.

\section{Pattern of Regression in Unmanaged Habitat}

When a game population is protected, and left to 'balance itself' a definite pattern of regression follows, as studies of numerous areas in Central Africa have shown. There will be variations in different areas, depending on the soil, the specific composition of plants and animals, rainfall and other factors, but essentially the principles are the same. The decline phases are outlined below, and graphically illustrated by the trend lines in Fig. 1:

Stage 0. A wide spectrum of mammals and a wide range of birds, reptiles and insects live in 'apparent harmony' in a habitat with a wide spectrum of plant species on a stable soil with good water relations. (At this stage the direct influence of man's predation through heavy hunting is reduced by legislation and law enforcement; but his indirect effects usually increase, e.g. by burning too early and too frequently in the dry season, or by imposing complete fire protection, both unnatural factors over much of Africa.) 
Stage 1. Mammals, especially those with no major predator except man, approach their potential rates of increase, bringing heavier pressure on the range. Combined with increased frequency of fire this leads to more bare ground. The more desirable grasses decrease (usually perennials); annual grasses, weeds, herbs and shrub seedlings increase. Excess grazing pressure on valuable perennial grasses decreases their vigour and in so doing decreases their underground parts rendering them less able to withstand the dry spells characteristic of marginal rainfall areas.

Stage 2. This is characterised mainly by scrub encroachment with bare ground still increasing. At this level habitat is closer to optimum for some species, (e.g. impala, eland and harvester termites) while other unadaptable species, for which the habitat change has been adverse, decrease or disappear, (e.g. roan, tsessebe, rhino and reedbuck). Exposed soil is severely eroded unless a hard compacted layer forms; in either case increased water runoff leads to a lowered water table underground and the silting of permanent pools, and the flash flooding of rivers replaces the previous regulated flow. The decrease in permanent surface water leads to still further concentration of animals.

Stage 3. The bare ground continues to increase; palatable and semipalatable shrubs decrease; young regenerating trees are eaten off and mature tree damage begins. Browse lines are very apparent unless there are many elephants, in which case many branches are pulled down, causing browse lines to become ragged and difficult to observe. However, trees seldom eaten by elephants (such as Trichilia roka) exhibit marked browse lines. At this stage vegetation in the dry season is sparse, game is readily seen and both the public and officials are highly pleased with the national parks.

Stage 4. Most shrubs are decreasing, due to being overbrowsed, or dying as a result of the lowered water table, (a notable exception is Croton megalobotrys, a highly unpalatable shrub which increases near watercourses). Tree damage is accelerated. Apart from patches of unpalatable grasses and weeds, ground cover at the end of the dry season is sparse. The bulk of the vegetation is annual and thus the rains fall largely on bare ground until the annuals establish themselves and grow late in the season. The vegetation being annual tends to fluctuate markedly with the type of rains falling each season. Annual vegetation with its poorer root structures dries off earlier after the cessation of the rains, and this, combined with its later establishment in the following rains, lengthens the already long dry season which even in normal conditions is a strain for the animal populations. Rhinoceros, roan, tsessebe, bushbuck and reedbuck, sensitive to such extreme habitat changes, are likely to disappear (this is normally blamed on poachers), while many birds, reptiles and insects also vanish with their habitats. Soil losses are severe with the lengthened period in which soils are exposed, and in arid regions with shallow immature soil the soil succession is seriously set back.

Stage 5. Trees, the last perennial palatable vegetation, are destroyed and conditions approximate to desert. Rainfall tends to run off instead of 
soaking into the ground and becoming effective. If the rain is slightly late in starting, or early in ending, there is a 'drought'; if the rainfall is on the low side it is a serious 'drought' while conversely if the rainfall is above average there are 'floods'. (Some marginal areas in Rhodesia have had seven years of 'drought' although the rainfall has shown no significant change either in volume or pattern of fall.) Soil erosion is limited only by soil type in relation to topography, wind and rain. The spectrum and volume of plant species is poor and the same is true of most groups of animals. Productivity is low, humans can only be supported at a low level of living, and reclamation is difficult if not impossible - depending upon the original nature of the soil and the degree of loss.

The stage of decline apparent to the untrained eye immediately prior to a biological collapse of resistant species, or 'die off' is usually much higher on the less leached more highly mineralised soils of volcanic origin than on the soils from poorer bases or those which have been heavily leached. On poor soils game can be found starving in chest high grass which has little or no nutritive value. This makes it difficult, in areas such as the Wankie national park, to convince officials and the public of the approach of a die-off when so much grass and vegetation can be seen. Unfortunately most of the animals merely fade out with adverse habitat changes; they are not adaptable or resistant enough to last through to the die-off phase, and by the time the regression of soil and vegetation becomes apparent to the layman the situation is serious in the extreme.

Game destruction for tsetse fly control is still taking place, a practice that is much abused, but in actual fact, from an ecological and game survival point of view, has done little direct harm to wildlife in Rhodesia (by accident rather than design). It is the land use philosophy behind it that is questionable and should perhaps undergo intense ecological examination; this has never been done. The shooting campaign has aroused emotions and drawn a red herring across the path, but has in reality done less damage to game than is for instance being done by well-meaning persons on the national lands where the game suffers from emotional but unscientific protection. Had there been no shooting and also no use of the tsetse infested areas, as in the Zambesi Valley, the evidence from this area indicates that the destruction to range and game would probably have been greater and of more lasting effect. The main damage to wildlife arising from Rhodesia's ecologically unsound tsetse control policy is due to the habitat changes following frequent burning (to ease hunting) rather than from the actual killing.

\section{Conclusion}

Rhodesia's game has in general been reduced to a very low and dangerous ebb through the increase in ecologically unsound agriculture and the insidious effects of overpopulation with consequent habitat changes. Try as ecologists might to create an awareness, the situation has reached the serious die-off phase in Tuli Circle, the first of the national areas to collapse biologically. Rhodesia has at last found a practical and workable means of halting land deterioration under domestic stock and perhaps saving wildlife outside national parks, but work to save wildlife inside areas 
reserved for it is still hindered by an excess of uninformed emotionalism and a lack of objective ecological realism. There is a definite lesson here for others struggling to conserve land and wildlife for aesthetic, tourist, safari hunting or protein production purposes.

\section{REFERENCES}

DASMANN, R. F. African Game Ranching. The Commonwealth and International Library of Science, Technology, Engineering and Liberal Studies. Biology Division. Pergamon Press. 1964.

SAVORY, C. A. R. Game utilisation in Rhodesia. Zool. Africana Vol 1 (2); pp 321-37. 1964.

SAVORY, C. A. R. Range Assessment Tuli Circle National Land, 1966. Unpublished report to the Game Ranchers' Association of Rhodesia.

SAVORY, C. A. R. Utilisation of Wildlife on Rhodesian Marginal Lands and its Relationship to Humans, Domestic Stock and Land Deterioration (Drought) May 1967. Symposium on Drought and Development held by the Association of Scientific Societies of Rhodesia. pp. 118-28.

SAVORY, C. A. R. Efforts in Rhodesia to Apply an Ecological Philosophy and Practice to the Human Environment to Avert Semi-desert Formation. Ecological Symposium. Pretoria. 1967. In print.

\section{Man, the Fly and the Game}

'A $\mathrm{N}$ interesting example of the interaction between fly and game is afforded $A$ in the Sese Islands, on Lake Victoria, from which the population was evacuated as a result of the sleeping-sickness outbreak some years ago. The sitatunga antelope increased in such numbers that the bush was kept under and the breeding thickets of the fly destroyed. Now that the country is being reclaimed and the game is retreating in front of man, these breeding thickets are again springing up.' From the Report of the East Africa Commission, 1925.

\section{Giraffes in West Africa}

$\mathrm{N}$ a comment on Mr Happold's note on giraffes in West Africa in the December ORYX, Professor D. Morgan, of the University of Zambia, writes that when in Niger, in April 1968, he had reports of numerous giraffe herds between Tillaberi and Niamey. One morning, on the bank of the Niger river, ten miles north of of Niamey, he saw 30 or more giraffes drinking and browsing. 'The polygamous nature of the group was obvious; nearby, two females had given birth to their young, and the "aunties" were already fussing over the week-old giraffes. The crèches never seemed to mix with the adult herd, at least not whilst drinking and browsing . . . I am sure that the Niger, together with forest areas, forms a natural barrier to giraffe distribution. I do remember, however, in 1948-49 seeing a small herd of giraffe just north of Paga (Ghana) in Upper Volta on the direct road to Ouagadougou. It is more than likely that most, if not all of these animals were poached as none are reported from that region today.'

\section{Drugging Asiatic Elephants}

IT TUN YIN, of Burma, writes to point out that Dr Fred Kurt's claim that the drug M99 and its antidote M285 were first used successfully on Asiatic elephants in Ceylon in 1967 is not correct, as the same drug had been used by Colonel Hla Aung in Burma in 1966. On that occasion one wild elephant was successfully captured at Mayan in Myitkyina District. This and others taken subsequently were captured for taming, later to be used for hauling timber. 